\title{
Poverty, marriage timing, and transitions to adulthood in Nepal: A longitudinal analysis using the Nepal Living Standards Survey
}

\author{
Ashish Bajracharya \\ Population Council \\ Sajeda Amin \\ Population Council
}

Follow this and additional works at: https://knowledgecommons.popcouncil.org/departments_sbsr-pgy

Part of the Demography, Population, and Ecology Commons, Family, Life Course, and Society Commons, Gender and Sexuality Commons, Gender Equity in Education Commons, International Public Health Commons, Maternal and Child Health Commons, and the Women's Health Commons How does access to this work benefit you? Let us know!

\section{Recommended Citation}

Bajracharya, Ashish and Sajeda Amin. 2010. "Poverty, marriage timing, and transitions to adulthood in Nepal: A longitudinal analysis using the Nepal Living Standards Survey," Poverty, Gender, and Youth Working Paper no. 19. New York: Population Council. 


\section{POVERTY, GENDER, AND YOUTH}

Poverty, Marriage Timing, and Transitions to Adulthood in Nepal: A Longitudinal Analysis Using the Nepal Living Standards Survey

Ashish Bajracharya and Sajeda Amin

WORKING PAPER NO. 192010

$\mathcal{A}$ Population Council 


\section{(2) Population Council}

One Dag Hammarskjold Plaza

New York, New York 10017 USA

www.popcouncil.org

pubinfo@popcouncil.org

For information on Poverty, Gender, and Youth working papers, see www.popcouncil.org/publications/wp/index.html

This material may not be reproduced without written permission from the authors.

ISSN: $1554-8538$

(C) 2010 The Population Council, Inc. 


\section{Poverty, Marriage Timing, and Transitions to Adulthood in Nepal: A Longitudinal Analysis Using the Nepal Living Standards Survey}

Ashish Bajracharya

Sajeda Amin

Ashish Bajracharya is Fred H. Bixby Postdoctoral Fellow at the Population Council, New York. E-mail: abajracharya@popcouncil.org. Sajeda Amin is Senior Associate, Program on Poverty, Gender, and Youth, Population Council, New York.

We are grateful to Paul Hewett, Tom LeGrand, Cynthia Lloyd, Barbara Mensch, and Kelly Hallman for their comments and suggestions on earlier versions of this paper. We would also like to thank participants at the International Union for the Scientific Study of Population (IUSSP) Meetings in Marrakech, Morocco, the PAA Meetings in Detroit, and the Population Council Brown Bag Seminar for their suggestions. We are also grateful to the 2008-10 Fred H. Bixby Fellowship at the Population Council for supporting this research. 


\begin{abstract}
This study examines the influence of household poverty experienced during early childhood on early marriage and outcomes in schooling and workforce participation for girls during adolescence in Nepal. Much of the evidence concerning these relationships is drawn from cross-sectional data that cannot be used to and has not been able to address causality. In this study, we use longitudinal data from the Nepal Living Standards Survey (NLSS), a two-wave panel in which the waves were conducted eight years apart to address these questions. For a sample of girls aged five to nine in the NLSS1 who were contacted again in the NLSS2 when they were aged 13 to $17(\mathrm{~N}=400)$, multinomial logistic regression estimates indicate that household poverty during childhood is associated with a higher likelihood that girls will marry early or join the workforce as adolescents rather than remain in school. Analyzing the data by household-wealth quintiles reveals surprisingly nonlinear results indicating that these associations are largest for the second-poorest quintile rather than for the poorest one. This study also highlights the role of the household rather than of the individual in decisionmaking for these adolescent girls.
\end{abstract}


This study examines the influence of household poverty experienced during girls' early childhood on their early marriage, school continuation, and workforce participation during adolescence in Nepal, one of the poorest countries in the world. Factors such as schooling and workforce participation have been consistently linked to the timing of marriage (see Mensch et al. 2005 for a detailed review). Much of this evidence is based, however, on cross-sectional data and is, at best, only suggestive (Lloyd 2005). In general, studies that explore factors such as schooling and work tend to favor explanations that give central play to individual agency, focusing on the adolescent as the decisionmaker during these critical steps in her transition to adulthood. In many settings including Nepal, marriages are arranged, and young people have little if any say in decisions about when and whom they wed. Few studies examine household factors such as poverty that are more likely to influence decisions concerning marriage, schooling, or workforce participation. In poor households, the dynamics of such decisions appear to change as a result of poverty. For example, the poor often perceive marriage to be the optimal choice for girls' futures even when alternatives such as schooling or workforce participation are readily available, as they are in Nepal. The exploration of the influence of household factors such as poverty is essential, therefore, for improving the understanding of how such decisions are made during girls' adolescence. Furthermore, the absence of appropriate longitudinal data that covers the span of a girl's adolescence has also prevented researchers from conducting rigorous causal analyses of these interrelationships.

In this paper, we address these shortcomings of the current literature by examining the influence of household poverty on early marriage, schooling, and work outcomes using longitudinal data from the Nepal Living Standards Survey (NLSS), a panel household survey. We model marriage, schooling, and work as outcomes that are interdependent and highlight the household rather than the individual as the locus of decisionmaking regarding these outcomes. The availability of a panel sample from Nepal allows us to examine the influence of the early childhood experience of poverty on outcomes during adolescence, following the lead of developed-country literature where such links have been substantiated with evidence from rigorous analyses. This approach allows us to advance current developing-country literature by enabling the temporal ordering of explanatory and outcome variables in empirical specifications that are more likely to yield causal estimates and address the problems of simultaneity bias and reverse causality that typically characterize cross-sectional studies. The data from Nepal present a unique opportunity for a more rigorous test of the effects of poverty on marriage timing than has been available previously, particularly given that early marriage coexists in Nepal with relatively high rates of labor-force participation and improved education among girls. Because these characteristics are typically associated with lower rates of early marriage, this study allows for an explicit, straightforward exploration of poverty as a driving force behind early marriage. It is, therefore, among the first to employ measures of household poverty as the main explanatory variables in examining the timing of marriage in relation to other nonmarriage adolescent outcomes in Nepal and the first to do so employing longitudinal data. 


\section{BACKGROUND}

\section{Marriage, Schooling and Work: Conceptual Links}

Women's access to formal education and labor-force participation is consistently linked to the timing of marriage (Singh and Samara 1996) (see Lloyd 2005 for an extensive review; see also Mensch et al. 2005). The increase in educational attainment for girls is widely credited as being the single most important reason for delay in timing of marriage in most parts of the developing world (Singh and Samara 1996; Mathur et al. 2003; Lloyd 2005). Even though the link between education and marriage lacks clear empirical validation, schooling is considered to enhance girls' autonomy, providing them with greater decisionmaking power in various aspects of their lives including those that concern their choice of spouse and timing of marriage (Jejeebhoy 1995). Education has been shown to shape ideas and values in ways that are less traditional and more Western, increasing girls' options and alternatives to marriage (Caldwell 1983; Singh and Samara 1996; Lloyd and Mensch 1999). In most countries, schooling is incompatible with marriage, in practice if not by policy, providing a mechanistic reason for the existence of a positive association between education and delayed marriage (Lindstrom and Brambila Paz 2002). Educational attainment, however, might be endogenous to timing of marriage: girls who delay marriage may remain in school longer than those who marry early, and girls who marry early may be withdrawn from school (Mensch et al. 2005). Because this relationship has not been addressed adequately in the literature, these findings must be interpreted with caution. Although in empirical terms the direction of causation remains unclear, the positive association between these variables appears to be consistent.

Several studies conducted in South Asia have established the positive association between school attendance and delayed marriage (see Lloyd 2005). In fact, evidence suggesting that early marriage deprives girls of education and encourages school dropout is largely absent in studies conducted in settings outside of South Asia. As Lloyd's (2005) global review suggests, empirical evidence of the association can be found only in Bangladesh, where a study by Amin et al. (2002) found that girls dropped out of school when suitable marriage partners were found for them. The age at dropout and the age at marriage are similar in Bangladesh, unlike their relationship in other countries. Similarly, Mahmud and Amin (2006), using panel data from Bangladesh, found that girls dropped out in significant numbers even before reaching secondary school when they came from poor households, but that they dropped out of school specifically in order to be married when they were from wealthier households. In Sri Lanka, a traditionally latemarrying society, Malhotra and Tsui (1996) found that girls' school attendance was a stronger predictor of later marriage than other indicators of modernity such as economic independence, ability to choose one's spouse oneself, and residence in a nuclear family. De Silva (1990), examining the timing of marriage in Sri Lanka, found similar patterns. Chowdhury and Trovato (1994) examined premarital roles and the status of women using educational attainment as an explanatory variable, employing data from the World Fertility Surveys conducted in the 1970s in five countries, four of which were in South Asia: Bangladesh, Nepal, Pakistan, and Sri Lanka. The results showed unanimously that premarital educational attainment was related to a delay in the timing of marriage in all five countries, even after appropriate adjustments were made for socioeconomic and cultural variables; the largest effects were seen in Sri Lanka. 
In a number of studies, women's labor-force participation is also postulated to delay marriage. Access to paid employment in new sectors of the formal economy may work by exposing women to new ideas and opportunities that encourage delayed marriage (Singh and Samara 1996). As the income-earning potential of girls increases through job opportunities, their status within their households and in society improves, giving them greater autonomy in marriage decisions (Mathur et al. 2003). Daughters' incomes also provide economic incentives to parents to postpone marriage arrangements if their daughters remain economically productive and contribute significantly to the household's finances (Jejeebhoy 1995; Singh and Samara 1996). Daughters' earnings enable families to delay marriage decisions for young girls that would otherwise be expedited as a result of anxieties concerning dowry or other marriage-related economic pressures. Workforce participation in conjunction with enhanced schooling is believed to reduce the attractiveness of early marriage through the prospects of future returns of these human and social capital investments. The literature concerning labor-force participation and timing of marriage in South Asia is, as expected, limited. The study by Chowdhury and Trovato (1994), for example, which found associations between schooling and delayed marriage, also found substantial associations between women's premarital paid work and delayed marriage across all four South Asian countries examined. Longer delays in timing of marriage were found among women who worked outside their homes or in family enterprises. In Bangladesh, a study of factory workers (Amin et al. 1998) found that girls who migrated to work in the garment industry married significantly later than their peers who were not exposed to such opportunities. As with the similar findings regarding schooling, a caveat must be made: these associations may be the result of reverse causality, that is, delayed marriage might increase the chances of girls' labor-force participation instead of the reverse. This possibility has not been addressed adequately by rigorous empirical research. Taken together, however, the associations between educational attainment and labor-force participation and delayed marriage are not only plausible but also appear to be consistent in most contexts in the developing world and, as the review suggests, in South Asia.

\section{Poverty and the timing of marriage}

The interrelationship of the decisions within households related to marriage, schooling, and work-force participation for girls are complex and do not occur independently of each other. Lloyd (2005) suggests that ideally these three critical aspects of a girl's transition into adulthood should occur in succession whereby she first gains social skills and knowledge in school that will help her to make a successful transition into the labor force, and that schooling in conjunction with labor-force participation offsets the economic attractiveness of early marriage (see also Singh and Samara 1996). In developing countries, however, this sequence of events is rare.

In the world's poorest countries, decisions related to marriage, schooling, and economic participation occur as competing alternatives that carry significant opportunity costs. As noted above, in poor households, marriage is often perceived to be an optimal choice for young girls, although it generally involves significant financial costs to the family that alternatives such as schooling do not require. In societies where gender inequality is institutionalized, longstanding traditions dictate these perceptions and subsequently the mechanics of decisions concerning their 
lives. Because marriage is universal in Nepal, daughters are considered to be economic burdens to the family. By marrying their daughters off early, families can shift significant portions of the expense of rearing, educating, and investing in their daughters to their sons-in-laws' families. Marrying off a young girl relieves her family of a long-term economic investment, the benefits of which they cannot reap. Moreover, the practice of paying dowry, the costs of which increase with the girl's age, encourages families to marry off their daughters early in order to avoid a larger future investment that would likely be required if she were to marry when she is older (Dyson and Moore 1983; Mathur et al. 2003; Mensch et al. 2005). Among the poorest families, such decisions are likely to be made as economic survival strategies

Additionally, in a country such as Nepal, where a girl typically has low status, her economic participation holds little value for her household and is unlikely to provide sufficient economic incentive to delay her marriage. She is likely to drop out of school, despite low attendance costs and relatively good access, because the perceived returns to the family of girls' schooling are negligible. In poor households, even in the absence of a decision to marry off a daughter, her schooling and economic participation are likely to face major barriers as a result of the significant opportunity costs they involve with regard to her more traditional and gendered responsibilities in the household. If she remains in school or works outside the home, she cannot contribute domestic labor or fulfill other domestic responsibilities such as caring for younger children or tending livestock. Thus, decisions related to her schooling, work, and marriage are tied to each other, and poverty plays an important role in determining the dynamics of their relationships.

Perhaps for this reason, in the scientific and descriptive literature poverty is widely recognized as a major factor affecting the timing of marriage among young women (see, for example, UNICEF 2001). Empirical evidence is lacking, however, that establishes a causal relationship between household poverty and early marriage or timing of marriage in developing countries. This lack of evidence is surprising in light of the attention that individual and microlevel factors such as schooling and work-force participation of girls have received in the marriage-timing literature. Even nuanced individual-level variables such as girls' experiences outside the family and their access to modern amenities such as the media have been examined (Yabiku 2004 and 2005; Ghimire et al. 2006), research that attributes substantial decisionmaking power to girls within their households.

In Nepal, however, and in most developing countries where gender inequalities are widely entrenched, marriage decisions are likely to be controlled only rarely by young women. The ways in which a girl makes the transition into adulthood and into marriage are likely a function of parental decisions, typically those of a male household head. Such decisions also likely reflect the economic circumstances of the family and are made with the family's economic welfare in mind. We hypothesize, therefore, that household-poverty measures are likely to be better predictors than individual-level indicators of outcomes for girls and that ultimately the household's economic status drives these relationships.

The dearth of research that examines the macro-level context of girls' transitions such as poverty is also surprising in light of the work of international development and advocacy agencies with an interest in early marriage, which has used descriptive evidence to put these potential linkages into context. For example, cross-country bivariate analyses, conducted by 
UNICEF (2005) using Demographic and Heath Survey (DHS) data (from surveys conducted between 1995 and 2003), of household wealth and early marriage show that child marriage is most common among the poorest 20 percent of the population in a majority of developing countries. This finding was true for the proportion of girls aged 20-24 who were married before they were 18 and the proportion of 15-19-year-olds who were in unions. This analysis also showed that significantly large disparities existed in the prevalence of early marriage between the lowest and highest household-wealth quintiles. Some studies conducted in the developing world also suggest, however, that the influence of poverty on certain outcomes of well-being may not necessarily be linear. Although researchers have not focused on such trends in detail, examples of nonlinear findings have been noted, for example, in the literature concerning microcredit programs for which group participation is observed to be the highest among individuals who are close to the poverty line and not among the poorest segments of the population. Substantive evidence that confirms such anecdotal findings are lacking. An examination of the effects of wealth in this study may allow a better understanding of such findings and help us to corroborate some of them.

Research that examines the direct empirical relationship between measures of household poverty and early marriage or related adolescent outcomes using panel data remains virtually nonexistent. A survey of the literature revealed no known studies that approach this question directly and explicitly. One study of note from Bangladesh, however, examines the nexus of these constructs using panel data. Mahmud and Amin (2006), using a large panel sample, explore the influence of early marriage and poverty on girls' schooling and dropout in Bangladesh. They find that girls from poor households are more likely than girls from wealthier households to drop out before reaching secondary school. Girls from wealthier households were observed to drop out later, in most cases in order to marry.

Poverty and its impact on a number of outcomes for adolescents (although not necessarily the timing of marriage) has been the subject of considerable research in the developed-country literature, however, most notably in the United States. Duncan and Brooks-Gunn's (1997) volume provides a comprehensive compilation of recent empirical research that examines the mechanisms through which poverty during childhood affects children negatively throughout different stages in their lives (see also Duncan and Brooks-Gunn 2000). Their research has shown that the negative associations of poverty with outcomes for adolescents are strongest when poverty pervades the child's early life, when it is persistent, and when it is severe. Negative associations are observed for school achievement, educational attainment and dropout, cognitive and behavioral outcomes, emotional distress, pregnancy outside of marriage, and risky adolescent sexual behavior. Exploring extensive national longitudinal datasets, such as the National Longitudinal Survey of Youth (NLSY) and the Panel Study of Income Dynamics (PSID), researchers have employed rigorous econometric techniques to establish robust causal relationships. Childhood poverty may exert similar influences on outcomes for adolescents in developing-country contexts as well. For example, if the association between childhood poverty and negative schooling outcomes in achievement and attainment is applicable in Nepal, it might explain marriage-schooling dynamics. If poverty impedes achievement and school continuation, leading to poor performance in school and dropout, the perceptions that marriage is ultimately a better choice compared with schooling and that schooling is a low-return investment are likely to 
become stronger. Thus, despite the relatively easy accessibility of education to the poor in Nepal, early marriage for their daughters is likely to remain an attractive choice for poor families.

Another aspect of the United States literature that is relevant to the current analysis is the use of longitudinal data to examine the effects of poverty during childhood or adolescence on subsequent outcomes experienced in young adulthood. Questions that relate early experience with poverty and later-life outcomes are not only important and interesting to ask but they are also important empirically because the use of longitudinal data enables researchers to perform statistically sound analyses free from the conventional problems of simultaneity bias or selection bias typically encountered when using cross-sectional data. For example, Teachman et al. (1997), using such longitudinal techniques, found negative effects of poverty status during adolescence and the family's income-to-needs ratio on educational success during young adulthood, the latter effect being more consistent. A similar approach was used by Duncan et al. (1998) in which poverty during early childhood was used to predict outcomes in adolescence, controlling for income during various other stages of a child's development including middle childhood and adolescence. These methods adjust for the fact that household income during adolescence may not be independent from other immediate family factors such as employment and program participation that also influence outcomes, and might be the source of significant bias in the estimation of income effects. The use of income data as measured during girls' early childhood (or a measure of current asset income, for example), which is more likely to be independent of other current factors that affect outcomes during their adolescence, is more likely to produce unbiased estimates of the effects of income.

As noted above, although the context and mechanisms through which poverty might influence outcomes for adolescents may vary between developed and developing countries, severe poverty experienced early in life in developing countries is likely to affect these outcomes in analogous ways. The developed-country literature serves as an important guide for such analyses in developing countries. The dearth of such analysis in the developing-country literature, however, is more likely a reflection of the lack of appropriate longitudinal data for these countries rather than of a lack of rigor in research on early marriage in the developing world. This point has been emphasized by Lloyd (2005) and by Mensch and her colleagues (2005) in their discussions of the shortcomings of the schooling and work-participation literature that relates to timing of marriage. The present examination of poverty and welfare, which makes use of a unique panel dataset, contributes to the research on poverty, marriage, and girls' transitions to adulthood in developing countries.

\section{Setting}

The research questions employed in this study are set in the context of Nepal, considered to be one of the poorest and most underdeveloped countries in the world, with a gross national income per capita (GNI) of US\$1,630 (PPP) in 2006. Early marriage is common in Nepal. The Demographic Health Survey of Nepal (NDHS) of $2006^{1}$ showed that girls married at a median age of 17.2 years. In 2006, more than 32 percent of women aged 15 to 19 were in union. Similarly, approximately 51 percent of young women aged 20 to 24 had been married by 18 and 10 percent by 15 (MOHP et al. 2006). Although marriage patterns vary by location and ethnic 
background within Nepal (see Thapa 1989 and 1996), the predominantly Hindu population shares many characteristics of marriage across the country. Marriages in Nepal continue to be arranged primarily by parents and are monogamous and patrilocal. Most involve material or financial transfers, often in the form of dowry. Typically, married girls perform domestic work in the spousal home and are not enrolled in school even if they are of school-going age. Participation in the wage economy is likely to be lower for married than for unmarried women. Married women's household and social status remains low in Nepal (see Bista 1991).

The figures for early marriage noted above and the previously suggested associations between school attendance and labor-force participation and timing of marriage imply that the situation for women is dismal in Nepal. In terms of statistics, however, Nepal is an anomaly. First, the pattern in schooling among Nepali girls has shown considerable progress in the last several decades, and by 2006 only 11 percent of girls aged 10 to 14 had never been enrolled in school. Among girls aged 15 to 19, approximately 21 percent had never been enrolled in school in 2006. These statistics for schooling are significantly better than those for neighboring regions and for other countries in South Asia including Pakistan, or for the Bihar and Rajasthan provinces of India, which have similar levels of poverty and similar early marriage profiles. ${ }^{2}$ When women's labor-force participation is considered, however, the mismatch between the work statistics and the poverty and early marriage patterns becomes clear. In Nepal, women participate in work outside of the home in uncharacteristically high numbers: in 2006, close to half (48 percent) of adolescent girls aged 15 to 19 and almost 60 percent of young women aged 20 to 24 were working for wages (MOHP et al. 2006). Among women in Bangladesh and Bihar, these figures are significantly lower; economic activity among girls aged 15 to 19 is at 10 percent and 15 percent, respectively. In fact, women's labor-force participation in Nepal in 2006 was the highest among all countries where DHS surveys were conducted at this time. These statistics indicate clearly that young women's situations in Nepal do not follow conventional or expected patterns. These anomalous patterns suggest that in Nepal the interrelationship between workforce participation, education, and timing of marriage are distinct from those elsewhere. This distinction provides a unique opportunity for the analyses to be a purer test of the effect of poverty on early marriage without the confounding influences of the lack of opportunities in schooling or work.

\section{The previous literature}

Much of the considerable literature on timing of marriage in Nepal examines the influence of socioeconomic variables, family and nonfamily experiences, and neighborhood and organizational effects. Macro-level effects such as the influence of ethnicity and cultural differences have also been examined. Most of the socioeconomic and family analyses have drawn upon the Chitwan Valley Family Study (CVFS). This survey, conducted in an area of rapid social change in rural southern Nepal, has given rise to a body of research examining marriage timing by means of event-history analysis on a life-history calendar. For example, Ghimire and colleagues (2006) found that premarital nonfamily experiences, primarily exposure to the media and socialization in club membership, were strongly positively associated with respondents' participation in spousal choice. Similarly, Yabiku (2005) found that school 
enrollment lowered both men's and women's marriage rates and that over time education became a strong deterrent to marriage for both sexes. Employment outside of the home appeared to expedite marriage for men but not for women. Yabiku's (2004) findings incorporated multilevel analysis and revealed that the proximity of services and organizations such as schools, health posts, movie theaters, and bus stops were significantly associated with reduced marriage rates. The use of these services appeared to mediate neighborhood and organizational effects on timing of marriage.

Much of the research examining factors such as ethnicity employ macro-level datasets such as the census, using correlation or simple regression-based analyses to determine these relationships. Thapa's researches $(1997,1996$, and 1989) are examples of studies that with varying degrees of model-specification complexity employ district-level analysis. They demonstrate that ethnicity and ethnic-group-related differences have strong significant associations with the age at which women are married in Nepal, independent of socioeconomic variables, including the respondent's district's level of development. Choe et al. (2005) finds that education, ethnicity, and region of residence are key correlates of the timing of first marriage and that although Nepal's society is in transition and the pervasiveness of modernity has had positive effects on delaying marriage, that cultural and ethnicity-based factors continue to influence timing of marriage significantly in the opposite direction. Aryal (2007) and Maitra (2005), using different datasets, also have taken approaches that are similar to those used in the CVFS studies to examine socioeconomic variables. Their results are consistent with the other studies noted here.

Finally, Dahal et al. (1993), using a smaller qualitative sample, examined standard demographic variables to explore marriage patterns and kin status, the nature of material exchange, and relative landholding of families. Information on the inheritance received by mothers and whether they spoke Nepali was also collected. Their findings from a small Nepali village setting suggest that the timing of marriage is largely a consequence of interfamilial power relations and intergenerational transfer dynamics. Access to kin and larger marriage networks, significant assets, and intergenerational transfers such as the transfer of assets (Djo) from the mother were significant predictors of delayed marriage. Similarly, a participatory study conducted by Mathur and colleagues (2001) in urban Kathmandu and rural Nawalparasi districts found that the empowerment of girls through economic activities is related to high aspirations and is also connected to the desire to delay marriage. In this literature, an explicit consideration of poverty or deprivation as an explanatory variable in timing of marriage is notably absent. Moreover, the treatment of marriage as a part of a set of competing decisions alongside schooling and wage work and not as an isolated outcome is also largely absent. The present study aims to fill these gaps.

\section{DATA AND METHODS}

Data for this study come from the two-wave panel of the Nepal Living Standards Survey (NLSS) of 1995-96 and 2003-04. The NLSS is a comprehensive, nationally representative, multitopic household survey conducted by the Central Bureau of Statistics (CBS) of the Government of Nepal in conjunction with the World Bank and is part of the Living Standards Measurement Surveys (LSMS) conducted in a number of developing countries around the world. 
Although the NLSS collected data in two large cross-sections of 3,373 households in 1995-96 (NLSS I) and 3,912 households in 2003-04 (NLSS II), the analysis below is drawn from the 962 panel households that were chosen from NLSS I and reinterviewed for NLSS II. The two-wave NLSS panel collected detailed longitudinal data using a comprehensive household survey instrument covering a wide range of topics, including demographic characteristics of respondents and their households: indicators of income, consumption, employment, educational attainment, marriage, maternity history, health status, remittances, quality and access to facilities, and agricultural and nonagricultural production. The NLSS is among the most comprehensive household surveys ever conducted in Nepal and is the only nationally representative survey to collect longitudinal data concerning individuals on such a wide range of topics, making it uniquely suited for the analysis presented here.

The sample in this study is restricted to unmarried adolescent girls aged five to nine living in the panel households in NLSS I $(\mathrm{N}=414)$. Table 1 summarizes the sample used in this study and documents the retention and attrition of girls in the panel households between NLSS I and NLSS II. All girls aged five to nine in NLSS I were aged 13 to 17 in NLSS II. Therefore, any incidence of marriage among these girls by the time of the follow-up survey also constitutes a union that is considered to be early according to the country's marriage laws, that is, one in which the bride is aged 18 or younger and is married without parental consent. Among the 414 girls in the initial sample, 289 (70 percent) remained in their respective households and were followed in NLSS II, which gathered extensive information on their outcomes and household characteristics as children and adolescents. In 2003-04, 111 girls (27 percent) were no longer residing in their households. Nevertheless, some information concerning these girls was maintained by means of a panel-tracking instrument in the survey, providing data about their activities for NLSS II or reasons for their absence, including death. Their outcomes in terms of marriage, schooling, or work were coded from information available from this tracking instrument. Other supplemental information, such as earnings and type of activity, level of education attained, periods of enrollment and dropout between waves, and other detailed data, were not available in NLSS II for these girls who were no longer living in their households. The final analytic sample is, therefore, comprised of 400 girls between the ages of 13 and 17 in NLSS II (97 percent of the baseline sample) about whom information on their outcomes was available; 14 girls ( 3 percent) from the baseline sample could not be followed and were excluded from the final sample.

\section{Dependent variable}

The dependent variable in this study is a categorical variable constructed to indicate whether the respondent is in school, working (as paid labor or at home), or married. The dependent variable is measured from information in the follow-up survey NLSS II conducted in 2003-04, or, if the respondent was not interviewed for the follow-up survey, from the paneltracking instrument. This measure is constructed as a multinomial outcome with the following mutually exclusive categories that indicate outcomes for girls in NLSS II:

(1) attending school, not participating in economic activities, unmarried;

(2) participating in economic activities, not in school, and unmarried; 
(3) participating in economic activities, enrolled in school, and unmarried;

(4) neither working nor in school, reporting only domestic work as her major activity, or idle;

(5) married and left the household; and

(6) not followed in NLSS II because of death, household splits, migration, or reasons unrelated to work, education, or marriage.

These comparison categories are modeled in multinomial logit regression analyses (outlined in detail below) and are coded in no particular order. Because of the small number of girls who reported being idle (that is, not in school and not in the workforce) or who reported only domestic work as their primary activity (not in school or the workforce) this category is merged with the category of girls for whom data are missing or unavailable in NLSS II, creating a category that combines all nonmarriage, nonschool, and nonwork categories. For those who married between waves and had left the household by the time of the NLSS II survey, information about whether they were active in the labor force or attended school after they were married was not available in the tracking instrument, and these responses are thus grouped separately as a distinct marriage outcome.

\section{Explanatory variables}

The main explanatory variable in this study is an indicator of household poverty status for adolescent girls in the sample in the baseline survey (NLSS I). This measure indicates whether the household is poor according to a measure of the nominal household expenditure per capita, in Nepali rupees in 1995-96, and whether it was higher or lower than a household-size-adjusted poverty line (see CBS 1997 for a detailed description of how household consumption expenditures are calculated). This measure was created by the CBS in the NLSS data as a dummy variable where one indicated that the household was poor and zero indicated that the household was not poor. Consumption measures are widely used instead of income as proxies for household welfare in research conducted in developing countries. Consumption-based measures are used here in the analyses instead of an income-based measure because they are considered to be better indicators than income of a household's ability to meet its current basic needs and are measured with higher reliability than income. Consumption measures are also more likely than income measures to reflect the long-term economic welfare of families because they are less sensitive to fluctuations in income (CBS 2004).

A set of mutually exclusive variables indicating household-consumption expenditures in quintiles for girls in the sample is also used as an explanatory variable in the analyses. The categorization into consumption quintiles is based on the distribution of household-consumption levels of all NLSS I households distributed in five consumption groups of equal populations. Although they are not adjusted to a particular threshold indicating deprivation (such as a poverty line), these measures of a household's welfare status or the proxy of a household's total income. are more refined than a poverty-status dummy. By using this measure, welfare effects on the outcome variable can be analyzed according to households that fall into the richest 20 percent and into the poorest 20 percent of all households surveyed. The richest quintile is used as a reference category in the regressions, which are discussed below. 


\section{Control variables}

Potentially, a number of individual, household, and community or regional factors may confound the relationship between poverty and outcomes for young adults in marriage, work, and education. In order to ensure that the associations observed between the dependent and independent variables are not spurious, these factors are carefully controlled for in the analyses. All control variables are taken from the baseline survey, that is, NLSS I conducted in 1995-96, when the young women for whom the multinomial dependent variable is measured in follow-up were aged five to nine. Therefore, these control variables represent the early experiences and background characteristics of the adolescents and young women in the sample during their childhood and are expected to be associated with both the dependent and independent measures outlined above.

First, a set of characteristics for the individual girls in the sample are controlled for in the regression models. A continuous measure for age of girls in years is included in the models to control for intracohort age effects in the analyses. Considerable evidence exists, particularly from Nepal, that religion- caste-, and ethnicity-based differences are likely factors in determining schooling, work, and marriage outcomes (Thapa 1989). Controls for these variables are, therefore, included in the analyses based on the characteristics of the household head recorded in NLSS I. We follow the operationalization of caste and ethnic groups employed in Yabiku (2004) and Axinn and Yabiku (2001) by using dummy variables for the five major caste and ethnic subdivisions in Nepal. These groups, as much of the literature suggests, have been shown to embody meaningful differences and distinct institutional arrangements, customs, norms, and attitudes toward work, schooling, and marriage for adolescent girls in Nepal, making this operationalization of caste and ethnicity appropriate distinctions to use for this analysis. Dummy variables are included for the Brahmins and Chettris, the first groups who represent the upper castes in the hierarchical Hindu system. Similarly, lower-caste Hindu occupational groups are represented in a second dummy variable that includes groups such as the Kami, Sarki, Damai, and others. The Newars, who are distinct from the upper- caste Hindu groups noted above but who rival them in educational attainment and wealth, are the third group included. Two groups of Tibeto-Burmese origin are also included in the analysis based on their origin in either in the Hill or the Terai regions. The groups that originate in the Hills include the Magar, Tamang, Rai, Limbu, and Gurung. Groups such as the Tharu are included in the Terai-originating groups. Individuals who could not be clearly classified into one of these five categories are captured in a dummy variable representing all other caste and ethnic groups (see Bista 1972 for a general discussion of caste and ethnicity in Nepal; see Thapa 1989 for a more detailed discussion of caste and ethnicity and their relationship with marriage in Nepal).

The analyses also control for characteristics of the household head to account for the influence of adults on schooling, work, and marriage decisions that were made for adolescent girls in the sample. These controls include the age of the household head in years and a dummy variable indicating whether the head of the household is female. A control for the whether the household head had ever attended school is also included as a measure of his/her human capital. Finally, the nature of the household head's employment is also included in the analysis by using a variable that indicates that individual's participation at the time of NLSS I in the formal or paid 
economy (this variable includes wage or self-employed nonagriculture or wage agriculture) (coded one). This variable is coded as zero if the household head was either engaged in selfemployed agriculture such as subsistence agriculture, which is the most prevalent form of work in Nepal, or if he or she was unemployed during the first wave of the survey. As the intergenerational transmission literature suggests, parental resources, in term of both economic and human capital, are likely to influence children's outcomes and behavior significantly. Naturally, research that seeks to examine such relationships uses controls for the human capital characteristics of the parents of the children in the sample. We elect to use household-head characteristics primarily because direct lineal relationships between girls and their parents could not be established for all of the girls in the NLSS sample, particularly when the girls were not directly related to the household head. Household-head characteristics are commonly used in studies to control for characteristics of adults in the household because of their simplicity. They also notably reduce potential problems that arise as a result of mothers' and fathers' correlated characteristics. It also allows the analyses to include a larger sample of girls in the models.

Control variables for family structure are also included in the analysis using dummy variables that indicate mainly the two most common forms of family organization in Nepal. Family structure is coded in three variables based on relevant data from NLSS I. The first two variables indicate whether the girl lived in an intact two-generational nuclear household (that is, with her parents and siblings only) or whether she lived in an intact multigenerational lineal household (that is, with her parents and grandparents, but not with parental siblings and their families). A third variable indicates any other form of family organization, which includes multigenerational collateral households (living with grandparents, parents, siblings, and parental siblings and their families) and those that are not intact or that include various other relatives and nonrelatives. Controls for family structure are included for their potential influence on our outcome variables. Children living in intact households can be expected to be less exposed to risk and vulnerability and may enjoy better outcomes in their transitions to adulthood. Such outcomes may be affected variably by the organization of the household and the expectations of resource sharing within complex family structures. For example, children in a multigenerational lineal household are likely to be less vulnerable than children in multigenerational collateral households where conflicts may arise about resource allocation and sharing and where significant competition for scarce resources may influence decisions about work, schooling, and even marriage. Such households are also more susceptible to fissure than lineal ones.

Household composition is accounted for primarily by using controls for the number of children present in the household. A number of studies that examine work, schooling, and marriage independently posit that siblings and other children living within the same household often compete for resources and may influence decisions on their outcomes. For girls in our sample, sibling-rivalry effects on schooling and economic effects on work and marriage decisions are likely to be more salient when other children are living in the household. These effects may vary considerably according to the ages of the other children. A set of control variables indicating the number of children who are present in the household aged 0-4, 5-9, 1014, and 15-19 are included in the regressions. One example of a sibling-rivalry effect might occur when children younger than five are living in the household. In such a situation, older siblings, such as the girls in our sample, might be expected to leave school to assume adult 
responsibilities in the home, such as caring for younger siblings or helping with domestic chores. Along the same lines, having a large number of siblings or other children in the household may expedite the marriage decision of girls, particularly if the household's resources are limited.

Finally, control variables indicating the region of residence of the girls in our sample is included in the analyses. The distinction between urban and rural residence is universally considered to be a key variable in most adolescent transitions and is particularly important for the three key outcomes of marriage, work, and education examined here (Singh and Samara 1996; Lloyd 2005). Therefore, a dummy variable indicating that the household is located in an urban area is included. In a topographically diverse country such as Nepal, the ecological region that individuals inhabit also influences the customs, norms, and attitudes about the constructs that are examined here. A set of control variables for the ecological regions in which each household is situated is, therefore, included in the models to account for these differences. These are dummy variables for the Mountain, Hill (reference category), and Terai regions. A discussion of the cultures and issues associated with these three regions can be found in Gurung (2001).

\section{Empirical strategy}

The analyses in this study employ multinomial logit regression to estimate multivariate models of the relationship between the marriage-schooling-work outcome for young women in the sample in NLSS II and the explanatory and control variables measured in NLSS I. With five nonordinal categories making up the outcome variable, the multinomial logit models are well suited for this analysis. Models for each category in the multinomial outcome are estimated simultaneously as binary logit regressions in which a particular category in the outcome is compared with a reference category in a multiequation estimation where an outcome with $k$ categories generates $k-1$ equations. The multinomial logit function can be represented as follows:

$$
\begin{aligned}
& \operatorname{Pr}\left(y_{i}=j\right)=\frac{\exp \left(X_{i} \beta_{j}\right)}{1+\sum_{j}^{J} \exp \left(X_{i} \beta_{j}\right)} \quad \text { and } \\
& \operatorname{Pr}\left(y_{i}=0\right)=\frac{1}{1+\sum_{j}^{J} \exp \left(X_{i} \beta_{j}\right)},
\end{aligned}
$$

where for the $i^{\text {th }}$ individual, $j$ is the observed outcome, and $X_{i}$ is a vector of explanatory variables that are measured in NLSS I. The unknown parameter $\beta_{j}$ is estimated using maximum likelihood. In this estimation, the parameters are presented as "relative risk ratios," which are odds ratios obtained by taking the exponent of the $\beta$ coefficient estimates from the logit models. Relative risk ratios are simpler to interpret and indicate the odds of being in the dependent variable category of interest (for example, being married and no longer in the household in our outcome) and not in the reference category (being unmarried, enrolled in school, and not economically active) for a unit change in the explanatory variable (or a change from 0 to 1 for a dummy variable). The longitudinal nature of the data, collected in two panel waves that are approximately eight years apart, provides a unique opportunity to examine the association of experiences during early adolescence and of background characteristics on these decisions as 
these girls make the transition to adulthood in the second wave. The multinomial outcome for girls in NLSS II described earlier is modeled against explanatory variables of poverty status or consumption quintiles and control variables in NLSS I as follows:

$$
Y_{i \mathrm{NLSS} 2}=\alpha_{0}+\delta_{1} P_{i \mathrm{NLSS} 1}+\beta_{1} X_{i \mathrm{NLSS} 1}+\varepsilon_{i}
$$

Here $Y_{i \text { NLSS2 }}$ is the multinomial outcome of young adult outcomes for girls measured in NLSS II and $P_{i \text { NLSS1 }}$ represents the poverty and consumption indicators that are the main explanatory variables in the study and are measured in NLSS I during the girl's childhood. $X_{i \text { NLSS1 }}$ represents a vector of control variables, all of which in this analysis are measured in the baseline of NLSS I. Here, $\delta_{1}$ represents the parameter estimate of interest, which is the association of the explanatory variable representing poverty with the young adult outcome.

This procedure allows for the strategic time ordering of the dependent variables measured temporally against the independent variables measured at an earlier time. It permits the analyses to guard against simultaneity bias and reverse causation and sets it apart from those of previous studies reviewed earlier that use cross-sectional data and are plagued by these problems in the absence of rigorous econometric treatment and plausible instruments. As noted above, the length of time between panel waves also ensures that autocorrelation-related issues are greatly reduced, and it provides a unique approach to the analysis whereby the experience of poverty during the early years of adolescence may be related to later outcomes as girls take on adult responsibilities.

In the analytic sample, as noted above, all girls aged five to nine at baseline are younger than 18 in NLSS II, and therefore, the hazard of marriage for these girls also represents the hazard for early marriage. Most of these girls are also expected to be enrolled in school at the time of the NLSS II survey before entering the formal workforce. Thus the models use the "only enrolled in school and not employed or married" category as the reference outcome category against which relative risk estimates are compared; school enrollment is thereby acknowledged as not only the desired outcome but also as the expected one relative to work- and marriagerelated outcomes. Although models presented in the tables represent the final specifications of the multinomial logit models where all control variables are included, sequential models (not shown) were specified in a series of sensitivity analyses by systematically adding and omitting various sets of control variables to test for any mediating effects. For the sake of simplicity, only the final model specifications are presented here. Results are discussed below.

As is common with household data, clustering of individuals is taken into consideration by specifying models to account for clustering at the primary sampling unit (PSU) level, the unit most closely analogous to a neighborhood. Individuals who live in the same PSU are likely to have correlated errors because they are likely to share common fixed characteristic such as neighborhood traits, customs, and culture, or they may share other characteristics such as access to schools, roads, communications, and media, that may bias the results and inflate the standard errors in the estimation. Using the "cluster" function of STATA software, robust standard errors are estimated in the models to account for this issue allowing for accurate testing of the statistical significance of parameter estimates. 


\section{RESULTS}

Descriptive statistics for the characteristics of girls in our sample aged five to nine in the baseline survey of NLSS I in 1995-96 and their households are presented in Table 2. Girls in the sample were, on average, 6.9 years old, and approximately 49 percent of them were enrolled in school in 1995-96. Economic activity for girls younger than ten was not measured for the NLSS. Among household characteristics, nearly 43 percent of girls aged five to nine resided in households that were poor, as defined by the NLSS. Likewise, 25 percent of the sample households fell in the poorest 20 percent of the overall population, whereas only 13 percent of these households fell in the richest quintile. Only a very small proportion (4 percent) of girls in lived in urban areas.

The mean age of the household head was 44. Approximately 36 percent of heads of households had ever attended school, and only 6 percent were female. The participation of the household head in the paid economy or in an occupation other than agricultural work was also limited; only 37 percent of household heads were engaged in such work. High-caste Hindus and lower occupational caste Hindus predominated in the survey sample. High-caste Hindus, comprised of the Brahmin and Chettri groups, made up 21percent of the sample, whereas the low-caste Hindu groups comprised of 23 percent of the girls in the sample. These two ethnic groups are followed by Tibeto-Burmese ethnic groups of Terai origin (17 percent) and Hill origin (12 percent) and by Newars, who make up the smallest proportion of girls at 3 percent of the sample. A substantial proportion (24 percent) of girls fell into the "other" category, which is comprised ethnic groups that could not be clearly classified into any of the main five ethnic categories. In the distribution of family-structure variables, the two clearly dominant groups accounted for around 77 percent of households in the sample. Multigenerational lineal households, the dominant group, accounted for close to 40 percent of all households whereas intact nuclear households made up approximately 37 percent of households. Means, standard deviations, and ranges of the remaining variables are shown in Table 2 and are not discussed here.

Table 3 presents the distribution of the outcome variable representing the work, educational, and marriage choices of unmarried girls in the NLSS II sample. Among these girls, now aged 13 to 17, 22 percent were enrolled in school and not employed during the second wave of the survey, whereas 23 percent were employed and not enrolled. About 25 percent of girls were both enrolled in school and were working, a considerable overlap between work and school for young adolescents in Nepal. Slightly, more than 15 percent of girls had married by the second survey wave, at which time all were younger than 18 and had left the household.

\section{Bivariate cross-tabulations}

One of the principal aims of this paper is to examine how the early experience of poverty, particularly during the critical years of childhood and early adolescence might affect various outcomes for girls as they make the transition to adulthood, specifically how childhood poverty affects education, workforce participation, and timing of marriage, key indicators of successful transitions. We present below descriptive results of the distribution of girls in the NLSS II sample on the multinomial outcome by key NLSS I characteristics of sampled girls and their households, including poverty level, the richest and poorest consumption quintiles, urban 
residence, and the girls' enrollment in school. These bivariate cross-tabulations are intended to supplement the multivariate analyses presented subsequently and to put the results in context, first by examining purely numeric differences in the outcomes. Pearson's chi-squared tests are used to determine whether differences between these groups are statistically significant. All results are shown in Table 4, in which clear patterns of differences are evident. As the Pearson's chi-squared test confirms, the distribution of the outcome varies significantly and statistically by all groups tested. We discuss below some of the distinct patterns of differences seen in these analyses.

Substantial differences by household and individual characteristics are evident in outcomes for marriage, for school enrollment, and for economic activity when each occurs independently rather than simultaneously. A considerably higher proportion of girls who lived in relatively disadvantaged households, that is, in households that that were poor, that were in the poorest consumption quintile, or that were located in rural areas, was married by the time of the NLSS II survey, compared with their better-off counterparts. Similarly, a relatively smaller proportion of girls in such households was enrolled in school (while not employed) and a larger proportion was active in the labor force.

Trends were similar for girls' individual characteristics. Of those girls who were enrolled in school at the time of NLSS I, a higher proportion were enrolled and not working during the second wave of the survey, whereas, a smaller proportion were working and not enrolled. A statistically significantly smaller proportion of girls who were enrolled at the time of school in NLSS I were married by the time of NLSS II. This finding is consistent with the wider literature that posits a systematic positive association between girls' acquisition of formal education and delayed marriage (Singh and Samara 1996; Lloyd 2005; Mensch et al. 2005). The complex relationships among these variables are explored further in the multivariate analyses described below.

\section{Multinomial logistic regressions}

Tables 5 and 6 present results from the multivariate analyses of the NLSS II educational, work, and marriage outcomes for girls using multinomial logit regressions as outlined above. For the analyses, an adjustment is made in the outcome variable to account for the small number of girls who were either only involved in domestic work or were idle. This category is merged with the category of girls for whom information was not available for their wave II activities, yielding five categories in place of the six originally described in the Measures section. The merging of these two categories essentially distinguishes it as the "other" category in a set of mutually exclusive categories that represent combinations of schooling, work, and marriage for these girls as adolescents. In each table, analyses from the final specification in which all individual and household control variables are included is presented. Interpretations, as noted above, are based on relative risk ratios, which are exponentiated forms of the parameter estimates obtained from the multinomial logit regressions and were obtained directly using the mlogit command in STATA with the "rrr" option.

Table 5 presents results from the model in which the poverty-status indicator dummy is the main explanatory variable. The results show that household poverty status is significantly 
associated with the multinomial outcome in education, work, and marriage. In Table 5, we see that girls who lived in poor households at the time of NLSS I are significantly more likely to have been married by the time of NLSS II (by a factor of 3.7, $\mathrm{p}<0.01$ ), compared with girls from better-off backgrounds, relative to being enrolled in school, when all other variables are held constant. This result clearly indicates a direct association between experiencing poverty in childhood with a higher likelihood of the incidence of early marriage, because all girls in the sample are younger than 18 by the time of the follow-up survey. Similarly, girls from poor households were significantly more likely to be working and not enrolled in school at the time of NLSS II (by a factor of 2.36, $\mathrm{p}<0.05$ ), relative to only being enrolled in school. These results provide important evidence of the influence of household poverty on marriage decisions, as well as economic activity among adolescent girls as adolescents relative to a desired outcome of remaining enrolled in school.

Among the control variables included in the regressions, a considerable number showed significant associations with the education, work, and marriage outcomes. As expected, an increase in age is associated with a significantly higher likelihood of being married compared with being enrolled in school. An increase in age by one year was associated with a two-times greater likelihood of being married for girls between the ages of 13 and $17(p<0.01)$. This result is striking considering that all of these marriages are early marriages, both conceptually and according to Nepalese law, regardless of whether parental consent was obtained. Living in an urban area, however, is associated with a lower risk of being married and of being enrolled in school and working simultaneously, compared with only being enrolled. If the head of household has ever attended school, the risk that the respondent will be married by the time of follow- up is lower than it would be otherwise. This variable also shows associations with a lower risk that the girl will participate in the labor market only, relative to being only in school. Interestingly, the household head's involvement in the paid economy or in nonagricultural work shows marginally significant associations with the girl's work-related outcomes but not with marriage. When the household heads where these girls were living were involved in the formal economy, the girls were less likely to be either only working or working and enrolled simultaneously at the time of NLSS II, relative to being only enrolled in school. These results could indicate the potential positive income effect of household heads' involvement in the formal economy and its impact on girls' schooling. Indications of such effects have been noted in previous research on work patterns in Nepal in Bajracharya (2008) and in the wider literature for developing countries (for example, Glick and Sahn 1998). Another significant result among control variables was for those indicating ethnicity. Girls from low-caste Hindu ethnic groups and occupational castes were seen to have a risk of being married relative to being only enrolled in school at the time of NLSS II that was more than seven times greater $(\mathrm{p}<0.01)$ than that for high-caste Hindus (the reference category), relative to being only enrolled in school. Girls from lower-caste Hindu groups were also seen to have a risk that was eight-times-greater of only working relative to being enrolled, $(\mathrm{p}<0.01)$ and a five-times-greater risk of being in the "other" category ( $\mathrm{rrr}=5.004 ; \mathrm{p}<0.10$ ). These results are hardly surprising, however, because these groups, which are traditionally disadvantaged, are among the poorest and most marginalized groups in Nepal among whom the practice of early marriage is common and well documented, as are their generally poor outcomes (see Bista 1972; Thapa 1989 and 1997). 
Although the number of children present in the household showed a negligible number of significant results, family structure, particularly living in an intact nuclear household, showed a significant association with a higher likelihood of either being employed in the labor market or being employed and enrolled in school simultaneously, relative to only being enrolled. This result may indicate the likelihood that smaller nuclear households have fewer and reduced resources compared with extended households. In these smaller households, girls may be required to drop out of school to enter the labor market or to work while attending school to increase income or other resources in the household. Finally, women in the Mountain region were observed to have a significantly higher likelihood of being employed in the labor force and not being enrolled in school, whereas women in the Terai had a significantly lower likelihood of being both enrolled and working, relative to only being enrolled in school.

In Table 6, we present results from models in which consumption-quintile-based measures are used as explanatory variables. In these regressions, the highest consumption quintile, or households that fell into the richest quintile of the overall NLSS sample, is used as the reference category, whereas the first four quintiles are entered into the regression equation as dummy variables. The multinomial logit regressions are conducted in an identical fashion to the previous models using the same set of control variables. The results from this specification are analogous to the results seen in the previous models, showing a nearly identical pattern of results for the welfare-indicator explanatory variable and the control variables. The results in Table 6 show that living in households that are in the lowest two consumption quintiles during NLSS I, compared with living in households in the richest quintile, is associated with a higher likelihood of being married and of only being employed relative to being enrolled in school at the time of NLSS II. Although girls whose households fell in the poorest consumption quintile might be expected to yield the strongest and largest associations with these outcome categories, the results reveal an interesting and unexpected pattern of nonlinear results. We find that the magnitudes of the relative risks for girls in the poorest quintile of households are large; $4.101(\mathrm{p}<0.05)$ for being employed relative to being enrolled and $4.238(\mathrm{p}<0.05)$ for being married. The magnitudes of the associations with the same two categories (marriage and employment), were significantly larger, however, for girls who lived in households that fell in the second-poorest quintile. For these girls, the size of the relative risks were $6.621(\mathrm{p}<0.05)$ for being employed and $5.442(\mathrm{p}<0.05)$ for marriage by the time of NLSS II, relative to being enrolled in school. These nonlinear results are unique in that they suggest that the association between economic deprivation and the vulnerability of girls to being married early or having to drop out of school to earn a living may not be highest at the most extreme levels of poverty but rather at the margin of the poor/nonpoor divide. Because these findings are relatively new, such a pattern can be speculated to be a reflection of the characteristics of and the opportunities available to people who are considered poor but are not extremely poor. Such a group, which is most likely represented in the second consumption quintile in our sample, although classified as poor may nevertheless have access to opportunities for schooling and work. Moreover, these girls are more likely to possess wider access to favorable social networks that facilitate upward mobility to move them from poverty. For them, the influence of household-welfare status is, therefore, likely to be of greater consequence in competing decisions concerning education, work, and marriage, compared with that for the extremely poor, who are likely to lack such networks and opportunities altogether 
and for whom such competing choices are unlikely to exist. In other words, these competing decisions are more likely to be sensitive to changes in welfare for a group for whom these choices are tangible than for a group with no such choices. Therefore, these larger association sizes for those in the second wealth quintile make sense. This explanation is speculative, however. Only further rigorous analyses can provide adequate insights into these associations so that concrete inferences can be made.

The pattern of results for the control variables in the model shown in Table 6 is nearly identical to that seen in the models using the poverty indicator: age is associated with a higher likelihood of marriage relative to schooling but not with other categories. Living in urban households reduces the likelihood of working and of being enrolled in school simultaneously and of marriage. Similarly, girls living in households that were headed by women or those who worked in the paid economy or the nonagricultural sector had a significantly lower likelihood of being married or of only being employed at the time of NLSS II. As in the previous model, being from the low-caste occupational groups, compared with being from the high-caste Hindu groups, showed large and significant associations with being married by the time of NLSS II and of only being employed relative to schooling. Associations with number of children in the household, family structure, and region were identical with the earlier models. The size of each of the associations noted here was also nearly identical with models for the poverty-status-indicator dummy for all statistically significant results, showing only minor differences in sizes of the relative risks.

\section{DiscusSION}

This study presents a concurrent examination of the competing choices of marriage, education, and work for adolescent girls in Nepal and the potential relationships of these transitions with poverty experienced during childhood or adolescence. The dependent variable was measured as a composite of these three decisions and modeled against household welfare as measured by poverty status and consumption-expenditure quintiles, controlling for an extensive set of individual-level and household variables. The multinomial logit analysis presented here reveals several clear patterns in the relationship between poverty and young adult outcomes in the results, particularly for that of early marriage.

First, the results in analysis for the key variables of interest, measures or poverty, appear to provide a strong indication that deprivation during childhood is associated with poor outcomes in young adulthood, especially for girls who experience poverty as five-to-nine-year-olds. For these children, both the poverty indicator and quintile-based indicators are seen to be of similar significant consequence for a girl's likelihood of (1) only participating in the workforce and not being enrolled or married or (2) being married before the age of 18, relative to being only enrolled in school in early adulthood. The large and strong statistically significant associations for both welfare indicators with these outcomes, after controlling for a host of variables that have previously been associated with adolescent well-being in the context of Nepal, provide clear evidence that the connection between these constructs is nontrivial. The coefficients for the control variables in both models that used poverty and quintile indicators were nearly identical, showing little or no difference in the sizes of the associations. This pattern of results suggests 
that both constructs of the explanatory variable are estimating the same effect, although they are conceptualized differently. These results also suggest that the quintile-based measure may be preferable to a poverty-status indicator because the former can be used to delineate effects of consumption, a proxy for welfare, more precisely and elucidate more accurately the associations between these factors at different levels of consumption. For example, the estimates calculated with quintile-based measures revealed a nonlinear pattern of results whereby girls in the secondpoorest quintile of households had the worst outcomes, although theoretically the worst effects would be expected to manifest in the outcome of girls in the poorest quintile of the population. These results potentially reveal relationships among these constructs that previously have not been observed or explored using rigorous methods. They may have significant implications not only for policy and interventions but also for the direction that future research on poverty and adolescents takes in the developing world

These nontrivial associations between poverty and outcomes for adolescent girls also suggest that macro-level economic factors may be the fundamental link between these constructs. Although much of current research conducted in Nepal seeks to tie individual factors such as nonfamily experiences (schooling, employment, and exposure to the media) (Yabiku 2004; Ghimire et al. 2006) to marriage timing and other outcomes or factors like ethnicity (Thapa 1989 and 1997), household economic decisions ultimately may be at the core of how these outcomes are determined. Associations observed in these studies, for example between proximity and use of cinemas and bus stops (Yabiku 2004) or exposure to television and movies (Yabiku 2005) and delayed marriage, may in fact be secondary manifestations of the economic considerations of families and households or a function of the welfare of their neighborhoods. The link between household economic welfare and outcomes for adolescents is likely the more important association of interest, particularly when the policy relevance of this research is considered. The natural next step for this research would be to delineate the mechanisms through which poverty or deprivation may affect adolescent outcomes, particularly those related to early marriage.

Methodologically, this study makes significant contributions to the literature concerning marriage timing in Nepal by using a longitudinal panel from the NLSS. This survey has significant advantages over other datasets for the analysis presented here. First, as a dataset that is primarily geared to measure living standards and the dynamics of household income and consumption, the data are uniquely suited to an analysis of poverty-based measures. Second, NLSS is the only longitudinal dataset with a range of measures of income, consumption, poverty, marriage, schooling, and labor-force participation of girls in Nepal that would allow for the longitudinal analysis presented here. Even if only for descriptive purposes, the collection of data from the same girls at two different times represents a significant advantage in information available for the developing world. Finally, the importance of longitudinal data for this research cannot be overemphasized. Much of the research on socioeconomic status or poverty variables and their associations with marriage and other outcomes for adolescents has employed crosssectional samples from the developing world. Although these studies have established some concurrent links with adolescent outcomes, they are unable to take into account that a measure of contemporary income or welfare is also inherently linked to other immediate household, family, or individual factors that may simultaneously influence the outcomes. This limitation is a major 
source of simultaneity. The approach used here, however, provides stronger evidence of the link between poverty and outcomes among adolescents by examining the longer-term consequences of welfare for young women. The use of longitudinal data in this study, whereby the experience with poverty during childhood, a potential cause, and the subsequent adolescent outcome, a potential effect, can be time ordered appropriately while controlling for a substantial number of background characteristics, represents a significant advance on previous methods that have been used to make causal arguments. This approach could serve as an impetus not only for future research on early marriage but also contribute to the early childhood investment literature.

Even with such advantages, some limitations of the data must be acknowledged. Although the strategy that is employed here is generally an improvement upon the crosssectional analyses that previous marriage-timing studies have provided, and even upon the largely retrospective life-history calendar data from surveys like the Chitwan Valley Family Study, the analysis would have benefited greatly in teasing out true causal effects if data had been collected on a variety of individual, family, and household characteristics in the follow-up for all girls. The NLSS panel was unable to do this primarily because of the out-migration of girls for reasons outlined above. For girls who had married or migrated by the time of the second survey wave, only limited information about their reason for leaving the household was available in the tracking instrument. Although a survey such as the NLSS that covers so much ground cannot do so, targeted and detailed datasets that are specifically designed to study the issues discussed here should collect data from women who migrate, particularly for those who marry, on their in schooling and work-force participation, and on their childbearing and other demographic variables in their new households. Such data would allow for analyses that are free from the problems of simultaneity and selection bias. Methods such as fixed-effects models or change models have been employed effectively in estimating causal effects when such data are available. Time and financial constraints present barriers to the collection of such data in largescale efforts such as the NLSS, which is not designed to target one particular topic but aims to fulfill the data needs of researchers from diverse disciplines conducting research on a range of topics.

\section{CONCLUSION}

In sum, our study finds that significant associations exist between girls' experience of being poor as children and marrying early, particularly in light of the competing choices of education and work. Our findings also suggest that the effects of poverty might be nonlinear; the highest levels of vulnerability appear to be encountered by girls living at the margin between being poor and not poor. This study represents an important first step in examining the association of early childhood poverty and outcomes for adolescents, particularly early marriage. The decisions households make that determine how and in what sequence girls experience their transition from childhood to adulthood depend on a number of complex and interconnected factors. To elucidate such factors, data must be collected for social and economic variables that affect young people's decisions and also for context-specific variables that represent culture, attitudes, and customs. Even when such data become available, delineating associations of these 
variables with the timing of marriage and other decisions that adolescents face will remain a challenge.

\section{NOTES}

1 NDHS 2006 is the most recent nationally representative survey with data available concerning marriage, schooling, and labor-force participation. The survey, however, is cross-sectional; therefore, the NLSS panel is used here for the analysis employing longitudinal methods. NLSS and NDHS figures are generally comparable.

2 The schooling statistics for Nepal are most directly comparable to those for Bangladesh and India. Despite its better schooling statistic, however, Bangladeshi women had low labor-force participation and a median age at marriage of 14.8 years in 2006. The association between schooling and marriage in Bangladesh has been explored in several papers by Amin and her colleagues.

\section{REFERENCES}

Amin, S., I. Diamond, R. Naved, and M. Newby. 1998. "Transition to adulthood of female garment factory workers in Bangladesh.” Studies in Family Planning 29(2): 185-200.

Amin, S., S. Mahmud, and L. Huq. 2002. "Kishori Abhijan: Baseline Survey Report on Rural Adolescents in Bangladesh.” Dhaka: Ministry of Women and Children Affairs, Government of Bangladesh.

Aryal, T.R. 2007. “Age at first marriage in Nepal: Differentials and determinants.” Journal of Biosocial Science 39: 693-706.

Axinn, William G. and Scott T. Yabiku. 2001. "Social change, the social organization of families, and fertility limitation.” American Journal of Sociology 106(5): 1,219-1,261.

Bajracharya, A. 2008. “Essays on the Influence of the Nature and Conditions of Parental Work on the Wellbeing of Children and Adolescents: Perspectives from the United States and Nepal.” Unpublished doctoral dissertation, Cornell University.

Bista, D.B. 1972. People of Nepal. Kathmandu: Ratna Pustak Bhandar.

—. 1991. Fatalism and Development. New Delhi: Orient Longman.

Caldwell, John. 1983. "Direct economic costs and benefits of children," in R.A. Bulatao and R.D. Lee (eds.), Determinants of Fertility in Developing Countries. Washington, DC: National Academy Press. Pp. 370-397.

Caldwell, J., Reddy, P.H., and Caldwell, P. 1983. "The causes of marriage change in South India.” Population Studies 37(3): 343-361. 
Central Bureau of Statistics (CBS). 1997. Nepal Living Standards Survey: Statistical Report 1995/96, Volumes I and II. Kathmandu: National Planning Commission/ His Majesty's Government of Nepal.

- 2004. Nepal Living Standards Survey: Statistical Report 2003/04, Volumes I and II. Kathmandu: National Planning Commission/ His Majesty’s Government of Nepal.

Choe, M., S. Thapa, and V. Mishra. 2005. "Early marriage and early motherhood in Nepal." Journal of Biosocial Science 37: 143-162

Chowdhury, F. and F. Trovato. 1994. "The role and status of women and the timing of marriage in five Asian countries.” Journal of Comparative Family Studies 25(2): 143-157.

Dahal, D., T. Fricke, and A. Thornton. 1993. "The family contexts of marriage timing in Nepal.” Ethnology 32(4): 305-323.

- 2006. Nepal Demographic and Health Survey 2006. Ministry of Health and Population (MOHP) Nepal, New ERA, and Macro International (MI). Kathmandu, Nepal: MOPH, New ERA, and MI.

De Silva, W.I. 1990. “Age at marriage in Sri Lanka: Stabilizing or declining?” Journal of Biosocial Science 22: 395-404.

Duncan, G. and J. Brooks-Gunn (eds.). 1997. Consequences of Growing Up Poor. New York: Russell Sage Foundation.

—. 2000. "Family poverty, welfare reform, and child development." Child Development 71(1): 188-196.

Duncan, G., J. Brooks-Gunn, W.J. Yeung, and J. Smith. 1998. "How much does childhood poverty affect the life chances of children?” American Sociological Review, 63(3): 406423.

Dyson, T. and M. Moore. 1983. "On kinship structure, female autonomy, and demographic behavior in India.” Population and Development Review 9(1): 35-60.

Ghimire, Dirgha J., William G. Axinn, Scott T. Yabiku, and Arland Thornton. 2006. "Social change, premarital nonfamily experience and spouse choice in an arranged marriage society.” American Journal of Sociology 111(4): 1,181-1,218.

Glick, P. and D. Sahn. 1998. "Maternal labor supply and child nutrition in West Africa." Bulletin of Economics and Statistics 60(3): 325-355.

Gurung, H. 2001. Nepal: Social Demography and Expressions. Kathmandu: Himal Books. 
Jejeebhoy, S.J. 1995. Women's Education, Autonomy, and Reproductive Behavior: Experience from Developing Countries. Oxford: Clarendon Press.

Levine, R., C. Lloyd, M. Greene, and C. Grown. 2008. Girls Count: A Global Investment and Action Agenda. Washington, DC: Center for Global Development.

Lindstrom, D.P. and C. Brambila Paz. 2001. "Alternative theories of the relationship of schooling and work to family formation: Evidence from Mexico.” Social Biology 48(34): 278-297.

Lloyd, Cynthia B. (ed.) 2005. Growing Up Global: The Changing Transitions to Adulthood in Developing Countries. Washington, DC: National Academy Press.

Lloyd, Cynthia B. and Barbara S. Mensch. 1999. "Implications of formal schooling for girls' transitions to adulthood in developing countries," in Critical Perspectives on Schooling and Fertility in the Developing World. Eds. Caroline Bledsoe, John B. Casterline, Jennifer A. Johnson- Kuhn, and John G. Haaga. Washington, DC: National Academy Press. Pp. 80-104.

Mahmud, Simeon and Sajeda Amin. 2006. “Girls’ schooling and marriage in rural Bangladesh,” In Children Lives and Schooling Across Societies. Eds. Emily Hannum and Bruce Fuller. New York: Elsevier.

Maitra, P. 2005. "Effect of socioeconomic characteristics on age at marriage and total fertility in Nepal.” Journal of Health, Population and Nutrition 22(1): 84 - 96.

Malhotra, A. and A. Tsui. 1996. "Marriage timing in Sri Lanka: The role of modern norms and ideas.” Journal of Marriage and Family 58(2): 476-490.

Mathur, S., M. Greene, and A. Malhotra. 2003. Too Young to Wed: The Lives, Rights and Health of Young Married Girls. Washington, DC: International Center for Research on Women.

Mathur, S., A. Malhotra, and M. Mehta. 2001. “Adolescent girls' life aspirations and reproductive health in Nepal.” Reproductive Health Matters 9(17): 91-100.

Mensch, Barbara S., Susheela Singh, and John B. Casterline. 2005. "Trends in the timing of first marriage among men and women in the developing world,” in Cynthia B. Lloyd, Jere R. Behrman, Nelly P. Stromquist, and Barney Cohen (eds.), The Changing Transitions to Adulthood in Developing Countries: Selected Studies. Washington, DC: National Academies Press. Pp. 118-171.

Singh, Susheela and Renee Samara. 1996. "Early marriage among women in developing countries.” International Family Planning Perspectives 22(4): 148-157, 175. 
Teachman, J., R. Day, and K. Carver. 1997. "Poverty during adolescence and subsequent educational attainment," in Consequences of Growing Up Poor. Eds. G. Duncan and J. Brooks-Gunn. New York: Russell Sage Foundation. Pp. 382-418.

Thapa, S. 1989. “The ethnic factor in the timing of family formation in Nepal.” Asia Pacific Population Journal 4(1): 3-34.

- 1996. "Girl child marriage in Nepal: Its prevalence and correlates.” Contributions to Nepalese Studies. 23(2): 361-375

- 1997. "Timing of family formation in ethnic mosaic Nepal: A district-level analysis." Asia Pacific Population Journal 12(2): 75-87.

United Nations Children’s Fund (UNICEF). 2001. Early Marriage: Child Spouses. Florence, Italy: UNICEF, Innocenti Research Center.

- 2005. Early Marriage, A Harmful Traditional Practice: A Statistical Exploration 2005. New York, NY: UNICEF.

Yabiku, S.T. 2004. "Marriage timing in Nepal: Organizational effects and individual mechanisms.” Social Forces 83(2): 559-586.

- 2005. "The effect of non-family experiences on age of marriage in a setting of rapid social change.” Population Studies 59(3): 339-354. 
Table 1 Retention and attrition of girls in the Nepal Living Standards Survey (NLSS) sample panel households between NLSS I (1995-96) and NLSS II (2003-04)

\begin{tabular}{lrr} 
& \multicolumn{2}{c}{ Girls aged $\mathbf{5}$ to 9} \\
\cline { 2 - 3 } Variable & $(\mathbf{N})$ & Percent \\
\hline Unmarried girls in NLSS I sample & $(414)$ & 100.0 \\
Girls for whom NLSS II information is available & $(400)$ & 96.6 \\
Girls who remained in household (NLSS II) & $(289)$ & 69.8 \\
Girls no longer in household II but with information (NLSS) & $(111)$ & 26.8 \\
Reason for no longer living in household & $(61)$ & 14.7 \\
Married and moved away & $(8)$ & 1.9 \\
Migrated for school & $(1)$ & 0.2 \\
Migrated for work & $(31)$ & 7.0 \\
Household split & $(9)$ & 2.0 \\
Died & $(1)$ & 0.2 \\
Other & $(14)$ & 3.4 \\
Girls missing/not followed & & \\
(no information retained, even of absence) (NLSS II) & & \\
\hline
\end{tabular}


Table 2 Characteristics of girls' surveyed aged five to nine and of household in the sample panel, Nepal Living Standards Survey I (1995-96)

\begin{tabular}{|c|c|c|c|c|c|}
\hline Variable & Observations (n) & Mean & $\begin{array}{l}\text { Standard } \\
\text { deviation }\end{array}$ & Minimum & Maximum \\
\hline \multicolumn{6}{|l|}{ Characteristics of girls in NLSS I } \\
\hline Age (years) & (414) & 6.89 & 1.410 & 5 & 9 \\
\hline Enrolled in school & (409) & 0.49 & & 0 & 1 \\
\hline $\begin{array}{l}\text { Household characteristics in NLSS I panel } \\
\text { Household is poor (consumption expenditure per } \\
\text { capita < poverty line for HH size) }\end{array}$ & (414) & 0.43 & & 0 & 1 \\
\hline \multicolumn{6}{|l|}{ Consumption expenditure (quintile) } \\
\hline First (poorest) & (414) & 0.25 & & 0 & 1 \\
\hline Second & (414) & 0.20 & & 0 & 1 \\
\hline Third & (414) & 0.27 & & 0 & 1 \\
\hline Fourth & (414) & 0.15 & & 0 & 1 \\
\hline Fifth (richest) (r) & (414) & 0.13 & & 0 & 1 \\
\hline Household is urban & (414) & 0.04 & & 0 & 1 \\
\hline \multicolumn{6}{|l|}{ Characteristics of head of household } \\
\hline Age & (414) & 44.28 & 13.02 & 18 & 81 \\
\hline Ever attended school & (411) & 0.36 & & 0 & 1 \\
\hline Works in paid economy or in nonagricultural jobs & (405) & 0.37 & & 0 & 1 \\
\hline Is female & (414) & 0.06 & & 0 & 1 \\
\hline \multicolumn{6}{|l|}{ Caste/ ethnicity } \\
\hline High-caste Hindu (Brahmin/Chettri) (r) & (405) & 0.21 & & 0 & 1 \\
\hline Low-caste Hindu (occupational castes) & (405) & 0.23 & & 0 & 1 \\
\hline Newar & (405) & 0.03 & & 0 & 1 \\
\hline Tibeto-Burmese of Hill origin (Magar, Gurung, Rai) & (405) & 0.12 & & 0 & 1 \\
\hline Tibeto-Burmese of Terai origin & (405) & 0.17 & & 0 & 1 \\
\hline Other castes & $(405)$ & 0.24 & & 0 & 1 \\
\hline \multicolumn{6}{|l|}{ Household composition (number of children) } \\
\hline Aged 0-4 & (414) & 1.39 & 1.23 & 0 & 5 \\
\hline Aged 5-9 & (414) & 2.31 & 1.27 & 1 & 7 \\
\hline Aged 10-14 & (414) & 1.07 & 0.95 & 0 & 5 \\
\hline Aged 15-19 & (414) & 0.60 & 0.94 & 0 & 5 \\
\hline \multicolumn{6}{|l|}{ Family structure } \\
\hline Intact nuclear & (414) & 0.37 & & 0 & 1 \\
\hline Intact multigenerational lineal & (414) & 0.40 & & 0 & 1 \\
\hline Nonintact nuclear (r) & (414) & 0.03 & & 0 & 1 \\
\hline Two-generational with parents & (414) & 0.00 & & 0 & 1 \\
\hline Multigenerational collateral & (414) & 0.09 & & 0 & 1 \\
\hline Other & (414) & 0.11 & & 0 & 1 \\
\hline \multicolumn{6}{|l|}{ Region of residence } \\
\hline Mountain & (414) & 0.05 & & 0 & 1 \\
\hline Hill (r) & (414) & 0.34 & & 0 & 1 \\
\hline Terai & 414 & 0.61 & & 0 & 1 \\
\hline
\end{tabular}

$(\mathrm{r})=$ Reference category.

Note: NLSS I individual weights are used. 
Table 3 Percentage distribution of unmarried girls aged five to nine at the time of the Nepal Living Standard Survey (NLSS I) (1995-96), by whether they were enrolled in school, were working, or were married when they were surveyed for NLSS II (2003-04)

\begin{tabular}{lccccccc} 
& $\begin{array}{c}\text { Activity data } \\
\text { missing/ or } \\
\text { respondent } \\
\text { died }\end{array}$ & $\begin{array}{c}\text { In school } \\
\text { only }\end{array}$ & $\begin{array}{c}\text { Working } \\
\text { only }\end{array}$ & $\begin{array}{c}\text { Idle or } \\
\text { Both in } \\
\text { school and } \\
\text { working }\end{array}$ & $\begin{array}{c}\text { Idrorming } \\
\text { performing } \\
\text { household } \\
\text { work only }\end{array}$ & $\begin{array}{c}\text { Married } \\
\text { and } \\
\text { moved }\end{array}$ & Total \\
\hline Distribution (n) & $(42)$ & $(88)$ & $(92)$ & $(102)$ & $(15)$ & $(61)$ & $(400)$ \\
Percent & 10.5 & 22.0 & 23.0 & 25.5 & 38.0 & 15.3 & 100 \\
\hline
\end{tabular}


Table 4 Percentage distribution of unmarried girls aged five to nine at the time of the Nepal Living Standards Survey (NLSS I) (1995-96), by selected characteristic, according to education, work, and marriage outcomes at the time of NLSS II (2003-04)

\begin{tabular}{|c|c|c|c|c|c|c|c|c|}
\hline \multirow[b]{2}{*}{ Characteristic } & \multirow{2}{*}{$\begin{array}{c}\begin{array}{c}\text { Activity data } \\
\text { missing_or } \\
\text { respondent died }\end{array} \\
\text { Percent (n) }\end{array}$} & \multirow{2}{*}{$\frac{\text { In school only }}{\text { Percent (n) }}$} & \multirow{2}{*}{$\begin{array}{c}\begin{array}{c}\text { Working } \\
\text { only }\end{array} \\
\text { Percent (n) }\end{array}$} & \multirow{2}{*}{$\begin{array}{c}\begin{array}{c}\text { Both in } \\
\text { school and } \\
\text { working }\end{array} \\
\text { Percent (n) }\end{array}$} & \multirow{2}{*}{$\begin{array}{c}\text { Idle or } \\
\text { performing } \\
\text { household } \\
\text { work only }\end{array}$} & \multirow{2}{*}{$\begin{array}{c}\begin{array}{c}\text { Married } \\
\text { and moved }\end{array} \\
\text { Percent (n) }\end{array}$} & \multirow{2}{*}{$\frac{(\mathrm{N})}{\text { Percent (n) }}$} & \multirow[b]{2}{*}{ Chi-square } \\
\hline & & & & & & & & \\
\hline \multicolumn{9}{|c|}{ Household was poor at the time of NLSS I } \\
\hline No & $10.3(24)$ & $28.2(66)$ & $19.7(46)$ & $26.5(62)$ & $3.4(8)$ & $12.0(28)$ & $100.0(234)$ & \\
\hline Yes & $10.8(18)$ & $13.3(22)$ & $27.7(46)$ & $24.1(40)$ & $4.2(7)$ & $19.9(33)$ & $100.0(166)$ & $* *$ \\
\hline \multicolumn{9}{|c|}{$\begin{array}{l}\text { Household was in lowest consumption } \\
\text { quintile at time of NLSS I }\end{array}$} \\
\hline No & $10.4(32)$ & $25.0(77)$ & $20.8(64)$ & $28.3(87)$ & $3.3(10)$ & $12.3(38)$ & $100.0(308)$ & \\
\hline Yes & $10.9(10)$ & $12.0(11)$ & $30.4(28)$ & $16.3(15)$ & $5.4(5)$ & $25.0(23)$ & $100.0(92)$ & \\
\hline \multicolumn{9}{|c|}{ Household is urban } \\
\hline No & $10.4(37)$ & $17.8(63)$ & $24.5(87)$ & $26.8(95)$ & 3.7 (13) & $16.9(60)$ & $100.0(355)$ & \\
\hline Yes & $11.1(5)$ & $55.6(25)$ & $11.1(5)$ & $15.6(7)$ & $4.4(2)$ & $2.2(1)$ & $100.0(45)$ & $* *$ \\
\hline \multicolumn{9}{|c|}{ Girl was enrolled in school at the time of NLSS I } \\
\hline No & $15.0(29)$ & $9.3(18)$ & $35.2(68)$ & $18.7(36)$ & $4.7(9)$ & $17.1(33)$ & $100.0(193)$ & \\
\hline Yes & $6.3(13)$ & $33.8(70)$ & $11.6(24)$ & $31.9(66)$ & $2.9(6)$ & $13.5(28)$ & $100.0(207)$ & $* *$ \\
\hline
\end{tabular}

** Pearson's chi-squared significance levels $=0.01$.

$\ddagger$ Borderline significant at $\mathrm{p}<0.10$. * Significant at $\mathrm{p}<0.05$; $* * \mathrm{p}<0.01$ 
Table 5 Multinomial logistic regression showing relative risk ratios for schooling, work, and marriage outcomes recorded for the Nepal Living Standards Survey II (2003-04) that were predicted by NLSS I household poverty status and selected characteristics of girls aged five to nine years in 1995-96

\begin{tabular}{|c|c|c|c|c|}
\hline \multirow[b]{2}{*}{ Characteristic } & \multicolumn{4}{|c|}{ Relative risk ratio } \\
\hline & $\begin{array}{c}\text { Activity data } \\
\text { missing/respondent died }\end{array}$ & $\begin{array}{c}\text { Working } \\
\text { only }\end{array}$ & $\begin{array}{c}\text { Working and } \\
\text { in school }\end{array}$ & $\begin{array}{c}\text { Married and left } \\
\text { household }\end{array}$ \\
\hline Household is poor & $\begin{array}{c}1.638 \\
(0.842)\end{array}$ & $\begin{array}{c}2.363 * \\
(0.932)\end{array}$ & $\begin{array}{c}1.727 \\
(0.576)\end{array}$ & $\begin{array}{l}3.765^{* *} \\
(1.677)\end{array}$ \\
\hline Girl's age & $\begin{array}{c}0.875 \\
(0.138)\end{array}$ & $\begin{array}{c}1.045 \\
(0.133)\end{array}$ & $\begin{array}{c}0.916 \\
(0.099)\end{array}$ & $\begin{array}{l}2.183^{* *} \\
(0.435)\end{array}$ \\
\hline Household is urban & $\begin{array}{c}0.426 \\
(0.442)\end{array}$ & $\begin{array}{c}0.833 \\
(0.606)\end{array}$ & $\begin{array}{l}0.147^{* *} \\
(0.097)\end{array}$ & $\begin{array}{c}0.085^{*} \\
(0.105)\end{array}$ \\
\hline \multicolumn{5}{|l|}{ Head of household } \\
\hline Age & $\begin{array}{l}1.018 \\
(0.018)\end{array}$ & $\begin{array}{c}0.994 \\
(0.017)\end{array}$ & $\begin{array}{c}0.984 \\
(0.019)\end{array}$ & $\begin{array}{l}1.014 \\
(0.021)\end{array}$ \\
\hline Ever attended school & $\begin{array}{l}0.183^{* *} \\
(0.101)\end{array}$ & $\begin{array}{l}0.103^{* *} \\
(0.049)\end{array}$ & $\begin{array}{c}0.818 \\
(0.325)\end{array}$ & $\begin{array}{c}0.307^{*} \\
(0.157)\end{array}$ \\
\hline Works in paid economy or at nonagricultural job & $\begin{array}{l}1.260 \\
(0.591)\end{array}$ & $\begin{array}{c}0.449 \ddagger \\
(0.187)\end{array}$ & $\begin{array}{l}0.500 \ddagger \\
(0.199)\end{array}$ & $\begin{array}{c}0.951 \\
(0.468)\end{array}$ \\
\hline Is female & $\begin{array}{c}0.642 \\
(0.499)\end{array}$ & $\begin{array}{l}0.371 \neq \\
(0.212)\end{array}$ & $\begin{array}{l}0.184^{*} \\
(0.128)\end{array}$ & $\begin{array}{c}0.531 \\
(0.376)\end{array}$ \\
\hline \multicolumn{5}{|l|}{ Ethnicity } \\
\hline Low-caste Hindu (occupational castes) & $\begin{array}{l}5.004 \ddagger \\
(4.502)\end{array}$ & $\begin{array}{l}8.124 * * \\
(4.854)\end{array}$ & $\begin{array}{l}1.142 \\
(0.827)\end{array}$ & $\begin{array}{l}7.568 * * \\
(5.569)\end{array}$ \\
\hline Newars & $\begin{array}{c}3.954 \\
(4.711)\end{array}$ & $\begin{array}{c}0.629 \\
(0.664)\end{array}$ & $\begin{array}{l}2.350 \\
(2.212)\end{array}$ & $\begin{array}{l}1.572 \\
(1.805)\end{array}$ \\
\hline Tibeto-Burmese of Hill origin & $\begin{array}{c}0.227 \\
(0.241)\end{array}$ & $\begin{array}{l}1.073 \\
(0.636)\end{array}$ & $\begin{array}{l}1.279 \\
(0.670)\end{array}$ & $\begin{array}{c}0.541 \\
(0.347)\end{array}$ \\
\hline Tibeto-Burmese of Terai origin & $\begin{array}{l}2.597 \\
(2.467)\end{array}$ & $\begin{array}{c}3.043 \\
(2.563)\end{array}$ & $\begin{array}{l}2.927 \\
(2.148)\end{array}$ & $\begin{array}{c}2.165 \\
(1.841)\end{array}$ \\
\hline Other & $\begin{array}{c}0.797 \\
(0.730)\end{array}$ & $\begin{array}{l}2.127 \\
(1.425)\end{array}$ & $\begin{array}{l}1.118 \\
(0.614)\end{array}$ & $\begin{array}{l}1.774 \\
(1.340)\end{array}$ \\
\hline \multicolumn{5}{|l|}{ Number of children in household } \\
\hline Aged 0-4 & $\begin{array}{l}1.709 * \\
(0.412)\end{array}$ & $\begin{array}{l}1.065 \\
(0.217)\end{array}$ & $\begin{array}{c}0.914 \\
(0.171)\end{array}$ & $\begin{array}{l}1.247 \\
(0.415)\end{array}$ \\
\hline Aged 5-9 & $\begin{array}{l}0.634 \ddagger \\
(0.168)\end{array}$ & $\begin{array}{l}0.567^{*} \\
(0.152)\end{array}$ & $\begin{array}{c}0.916 \\
(0.155)\end{array}$ & $\begin{array}{c}0.737 \\
(0.182)\end{array}$ \\
\hline Aged 10-14 & $\begin{array}{c}0.688 \\
(0.160)\end{array}$ & $\begin{array}{c}1.031 \\
(0.252)\end{array}$ & $\begin{array}{l}1.124 \\
(0.239)\end{array}$ & $\begin{array}{c}0.797 \\
(0.237)\end{array}$ \\
\hline Aged 15-19 & $\begin{array}{l}1.430 \\
(0.369)\end{array}$ & $\begin{array}{l}1.106 \\
(0.314)\end{array}$ & $\begin{array}{c}1.078 \\
(0.282)\end{array}$ & $\begin{array}{l}1.060 \\
(0.310)\end{array}$ \\
\hline \multicolumn{5}{|l|}{ Family structure } \\
\hline Intact nuclear two-generational & $\begin{array}{c}0.287 \ddagger \\
(0.193)\end{array}$ & $\begin{array}{l}4.778 * * \\
(2.676)\end{array}$ & $\begin{array}{c}2.750 \ddagger \\
(1.500)\end{array}$ & $\begin{array}{c}1.723 \\
(0.982)\end{array}$ \\
\hline Intact multigenerational lineal & $\begin{array}{c}0.360 \ddagger \\
(0.199)\end{array}$ & $\begin{array}{c}1.320 \\
(0.867)\end{array}$ & $\begin{array}{c}1.165 \\
(0.652)\end{array}$ & $\begin{array}{c}0.880 \\
(0.503)\end{array}$ \\
\hline \multicolumn{5}{|l|}{ Region } \\
\hline Mountain & $\begin{array}{c}0.343 \\
(0.531)\end{array}$ & $\begin{array}{c}4.805^{*} \\
(3.496)\end{array}$ & $\begin{array}{c}1.169 \\
(0.727)\end{array}$ & $\begin{array}{l}1.698 \\
(1.829)\end{array}$ \\
\hline Terai & $\begin{array}{c}1.019 \\
(0.659)\end{array}$ & $\begin{array}{c}0.977 \\
(0.635)\end{array}$ & $\begin{array}{l}0.217^{* *} \\
(0.106)\end{array}$ & $\begin{array}{l}1.136 \\
(0.708)\end{array}$ \\
\hline Constant & $\begin{array}{c}2.975 \\
(4.777)\end{array}$ & $\begin{array}{l}1.205 \\
(1.826)\end{array}$ & $\begin{array}{c}6.956 \\
(8.946)\end{array}$ & $\begin{array}{l}0.001^{* *} \\
(0.002)\end{array}$ \\
\hline Number of observations & 382 & 382 & 382 & 382 \\
\hline Log likelihood & -459.6 & -459.6 & -459.6 & -459.6 \\
\hline Degrees or freedom & 80 & 80 & 80 & 80 \\
\hline Chi-square & 5585 & 5585 & 5585 & 5585 \\
\hline
\end{tabular}

$\ddagger$ Borderline significant at $\mathrm{p}<0.10$. *Significant at $\mathrm{p}<0.05 ;{ }^{* *} \mathrm{p}<0.01$.

Note: Robust standard errors are given in parentheses (clustered by primary sampling unit in NLSS I). Reference category: In school only. 
Table 6 Multinomial logistic regression showing relative risk rates for schooling, work, and marriage outcomes recorded for the Nepal Living Standards Survey II (2002-04) predicted by NLSS I (1995-96) by consumption quintiles and characteristics for girls aged five to nine years old in 1995-96

\begin{tabular}{|c|c|c|c|c|}
\hline \multirow[b]{2}{*}{ Characteristic } & \multicolumn{4}{|c|}{ Relative risk ratio } \\
\hline & $\begin{array}{c}\text { Activity data } \\
\text { missing/respondent died }\end{array}$ & $\begin{array}{c}\text { Working } \\
\text { only }\end{array}$ & $\begin{array}{l}\text { Working and } \\
\text { in school }\end{array}$ & $\begin{array}{l}\text { Married and left } \\
\text { household }\end{array}$ \\
\hline \multicolumn{5}{|l|}{ Household consumption } \\
\hline First quintile (poorest) & $\begin{array}{c}2.753 \\
(2.119)\end{array}$ & $\begin{array}{c}4.101 * \\
(2.897)\end{array}$ & $\begin{array}{c}1.418 \\
(0.886)\end{array}$ & $\begin{array}{c}4.238^{*} \\
(2.930)\end{array}$ \\
\hline Second quintile & $\begin{array}{c}2.784 \\
(2.299)\end{array}$ & $\begin{array}{l}6.621^{*} \\
(4.974)\end{array}$ & $\begin{array}{c}2.320 \\
(1.529)\end{array}$ & $\begin{array}{c}5.442 * \\
(4.595)\end{array}$ \\
\hline Third quintile & $\begin{array}{c}2.516 \\
(1.714)\end{array}$ & $\begin{array}{c}1.601 \\
(1.046)\end{array}$ & $\begin{array}{l}1.048 \\
(0.485)\end{array}$ & $\begin{array}{c}1.336 \\
(0.735)\end{array}$ \\
\hline Fourth quintile & $\begin{array}{c}1.627 \\
(1.137)\end{array}$ & $\begin{array}{c}1.328 \\
(0.758)\end{array}$ & $\begin{array}{c}0.387 \\
(0.241)\end{array}$ & $\begin{array}{c}0.716 \\
(0.492)\end{array}$ \\
\hline Girl’s age & 0.871 & 1.065 & 0.961 & $2.218^{* *}$ \\
\hline & $(0.139)$ & $(0.138)$ & $(0.108)$ & $(0.435)$ \\
\hline Household is urban & 0.532 & 1.035 & $0.124 * *$ & $0.091^{*}$ \\
\hline \multicolumn{5}{|l|}{ Head of household } \\
\hline Age & $\begin{array}{c}1.017 \\
(0.019)\end{array}$ & $\begin{array}{c}0.991 \\
(0.017)\end{array}$ & $\begin{array}{c}0.982 \\
(0.019)\end{array}$ & $\begin{array}{c}1.013 \\
(0.021)\end{array}$ \\
\hline Ever attended school & $\begin{array}{l}0.192 * * \\
(0.110)\end{array}$ & $\begin{array}{l}0.112^{* *} \\
(0.055)\end{array}$ & $\begin{array}{c}0.802 \\
(0.323)\end{array}$ & $\begin{array}{c}0.332 * \\
(0.169)\end{array}$ \\
\hline Works in paid economy or at nonagricultural job & $\begin{array}{l}1.341 \\
(0.633)\end{array}$ & $\begin{array}{c}0.426^{*} \\
(0.180)\end{array}$ & $\begin{array}{c}0.447 \ddagger \\
(0.187)\end{array}$ & $\begin{array}{c}0.895 \\
(0.460)\end{array}$ \\
\hline Is female & $\begin{array}{c}0.602 \\
(0.499)\end{array}$ & $\begin{array}{c}0.330 \ddagger \\
(0.187)\end{array}$ & $\begin{array}{l}0.159 * * \\
(0.110)\end{array}$ & $\begin{array}{c}0.488 \\
(0.351)\end{array}$ \\
\hline \multicolumn{5}{|l|}{ Ethnicity } \\
\hline Low-caste Hindu (occupational castes) & $\begin{array}{c}4.771 \ddagger \\
(4.410)\end{array}$ & $\begin{array}{c}8.536 * * \\
(5.299)\end{array}$ & $\begin{array}{c}1.486 \\
(1.123)\end{array}$ & $\begin{array}{c}7.870 * * \\
(6.066)\end{array}$ \\
\hline Newar & $\begin{array}{l}4.019 \\
(5.041)\end{array}$ & $\begin{array}{c}0.594 \\
(0.588)\end{array}$ & $\begin{array}{c}2.893 \\
(2.873)\end{array}$ & $\begin{array}{l}1.625 \\
(1.835)\end{array}$ \\
\hline Tibeto-Burmese of Hill origin & 0.216 & 1.078 & 1.337 & 0.531 \\
\hline & $(0.232)$ & $(0.649)$ & $(0.667)$ & $(0.354)$ \\
\hline Tibeto-Burmese of Terai origin & $\begin{array}{l}2.054 \\
(2.158)\end{array}$ & $\begin{array}{l}2.585 \\
(2.344)\end{array}$ & $\begin{array}{l}2.970 \\
(2.252)\end{array}$ & $\begin{array}{l}1.818 \\
(1.724)\end{array}$ \\
\hline Other & 0.652 & 2.173 & 1.224 & 1.721 \\
\hline \multicolumn{4}{|l|}{ Number of children in household } & (1.345) \\
\hline Aged 0-4 & $\begin{array}{l}1.705^{*} \\
(0.416)\end{array}$ & $\begin{array}{c}0.989 \\
(0.194)\end{array}$ & 0.889 & $\begin{array}{l}1.202 \\
(0.385)\end{array}$ \\
\hline Aged 5-9 & $0.604 \ddagger$ & $0.553^{*}$ & 0.871 & 0.707 \\
\hline & $(0.166)$ & $(0.144)$ & $(0.148)$ & $(0.169)$ \\
\hline Aged 10-14 & $\begin{array}{c}0.697 \\
(0.163)\end{array}$ & $\begin{array}{c}1.032 \\
(0.252)\end{array}$ & $\begin{array}{l}1.188 \\
(0.244)\end{array}$ & $\begin{array}{c}0.803 \\
(0.246)\end{array}$ \\
\hline Aged 15-9 & 1.442 & 1.035 & 1.013 & 1.008 \\
\hline & $(0.385)$ & $(0.295)$ & $(0.269)$ & $(0.296)$ \\
\hline \multicolumn{5}{|l|}{ Family structure } \\
\hline & $(0.185)$ & $(2.923)$ & $(1.624)$ & (1.060) \\
\hline Intact multigenerational lineal & $\begin{array}{c}0.373 \ddagger \\
(0.211)\end{array}$ & $\begin{array}{c}1.506 \\
(0.966)\end{array}$ & $\begin{array}{c}1.132 \\
(0.633)\end{array}$ & $\begin{array}{c}0.919 \\
(0.528)\end{array}$ \\
\hline \multicolumn{5}{|l|}{ Region: } \\
\hline Mountain & $\begin{array}{c}0.310 \\
(0.488)\end{array}$ & $\begin{array}{c}5.333^{*} \\
(3.645)\end{array}$ & $\begin{array}{c}1.157 \\
(0.683)\end{array}$ & $\begin{array}{c}1.947 \\
(2.074)\end{array}$ \\
\hline Terai & $\begin{array}{c}0.940 \\
(0.645)\end{array}$ & $\begin{array}{c}0.822 \\
(0.546)\end{array}$ & $\begin{array}{l}0.189 * * \\
(0.095)\end{array}$ & $\begin{array}{l}1.000 \\
(0.638)\end{array}$ \\
\hline Constant & 2.215 & 0.895 & 7.523 & $0.001^{* *}$ \\
\hline Number of observations & $(3.921)$ & (1.338) & & $(0.002)$ \\
\hline Log likelihood & $\begin{array}{r}382 \\
-452.8\end{array}$ & $\begin{array}{r}382 \\
-452.8\end{array}$ & $\begin{array}{r}382 \\
-452.8\end{array}$ & $\begin{array}{r}382 \\
-452.8\end{array}$ \\
\hline Degrees of freedom & 82 & 82 & 82 & 82 \\
\hline Chi-square & e(chi) & e(chi) & e(chi) & e(chi2) \\
\hline
\end{tabular}

¥Borderline significant at $\mathrm{p}<0.10$. *Significant at $\mathrm{p}<0.05$; ** $\mathrm{p}<0.01$.

Note: Robust standard errors are given in parentheses (clustered by primary sampling unit in NLSS I). Reference category: In school only. 


\section{Poverty, Gender, and Youth Working Papers}

Working papers are distributed electronically. When a new paper is published, subscribers are notified by e-mail and a link to the paper is provided.

To subscribe to the Poverty, Gender, and Youth working paper e-mail notification list, please send your request to pgywp@popcouncil.org.

PDFs of recent issues are available at www.popcouncil.org/publications/wp/index.html

2010

19

Ashish Bajracharya and Sajeda Amin, "Poverty, marriage timing, and transitions to adulthood in Nepal: A longitudinal analysis using the Nepal Living Standards Survey.”

2009

18 Sajeda Amin and Bussarawan Teerawichitchainan, "Ethnic fertility differentials in Vietnam and their proximate determinants."

17 Sajeda Amin and S. Chandrasekhar, "Looking beyond universal primary education: Gender differences in time use among children in rural Bangladesh.”

16 John Bongaarts, François Pelletier, and Patrick Gerland, "Global trends in AIDS mortality.”

15 Bussarawan Teerawichitchainan and Sajeda Amin, "The role of abortion in the last stage of fertility decline in Vietnam.”

14 Cynthia B. Lloyd and Paul C. Hewett, "Educational inequalities in the midst of persistent poverty: Diversity across Africa in educational outcomes.”
13 Wendy Baldwin and Judith Diers, "Demographic data for development in sub-Saharan Africa.”

2008

12 Sajeda Amin and Lopita Huq, "Marriage considerations in sending girls to school in Bangladesh: Some qualitative evidence.”

11 S. Chandrasekhar and Abhiroop Mukhopadhyay, "Multiple dimensions of urban well-being: Evidence from India”

10 Sajeda Amin and Luciana Suran, "Terms of marriage and time-use patterns of young wives: Evidence from rural Bangladesh.”

9 John Bongaarts, Thomas Buettner, Gerhard Heilig, and François Pelletier, "Has the HIV epidemic peaked?”

8 Barbara S. Mensch, Paul C. Hewett, Richard Gregory, and Stephane Helleringer, "Sexual behavior and STI/HIV status among adolescents in rural Malawi: An evaluation of the effect of interview mode on reporting.”

7 John Bongaarts, "Fertility transitions in developing countries: Progress or stagnation?” 
6 Cynthia B. Lloyd, "The role of schools in promoting sexual and reproductive health among adolescents in developing countries.”

5 Ann Biddlecom, Richard Gregory, Cynthia B. Lloyd, and Barbara S. Mensch, "Premarital sex and schooling transitions in four subSaharan African countries.”

4 Sajeda Amin, John B. Casterline, and Laura Spess, "Poverty and fertility: Evidence and agenda.”

3 Bussarawan Teerawichitchainan and James F. Phillips, "Ethnic differentials in parental health seeking for childhood illness in Vietnam.”

2 Zachary Zimmer, Kim Korinek, John Knodel, and Napaporn Chayovan, "Support by migrants to their elderly parents in rural Cambodia and Thailand: A comparative study.”

1 Sharon Ghuman and Cynthia B. Lloyd, “Teacher absence as a factor in gender inequalities in access to primary schooling in rural Pakistan.” 